\title{
Association between dental amalgam fillings and Alzheimer's disease: a population-based cross-sectional study in Taiwan
}

\author{
Yi-Hua Sun ${ }^{1}$, Oswald Ndi Nfor ${ }^{2}$, Jing-Yang Huang ${ }^{2}$ and Yung-Po Liaw ${ }^{2,3^{*}}$
}

\begin{abstract}
Introduction: The potential effects of amalgam fillings on the development of Alzheimer's disease (AD) are not well understood. The aim of the study was to evaluate the association between dental amalgam fillings and Alzheimer's disease in Taiwanese population aged 65 and older.

Methods: Data were retrieved from the Longitudinal Health Insurance Database (LHID 2005 and 2010). The study enrolled 1,943,702 beneficiaries from the LHID database. After excluding death cases and individuals aged 65 and under, 207,587 enrollees were finally involved in the study. Dental amalgam fillings are coded as 89001C, 89002C, 89003C, 89101 C, 89102C, or 89103C in the national health insurance research database (NHIRD). Alzheimer's disease was diagnosed using the International Classification of Diseases, Ninth Revision, Clinical Modification (ICD-9-CM) codes 331.0.

Results: Individuals exposed to amalgam fillings had higher risk of Alzheimer's disease (odds ratio, OR $=1.105,95 \%$ confidence interval, $\mathrm{Cl}=1.025-1.190)$ than their non-exposed counterparts. Further analysis showed that the odds ratio of Ahlzheimer's disease was $1.07(95 \% \mathrm{Cl}=0.962-1.196)$ in men and $1.132(95 \% \mathrm{Cl}=1.022-1.254)$ in women.

Conclusions: Women who were exposed to amalgam fillings were 1.132 times more likely to have Alzheimer's disease than were their non-exposed counterparts.
\end{abstract}

\section{Introduction}

Dental amalgam, a material for filling prepared cavities after removing caries, consists of about $50 \%$ mercury [1]. Mercury vapor has been proven to be toxic to the central nervous system. In 2008, the European Commission asserted that there is no evidence showing negative effects on the human central nervous system when applying amalgam fillings as reported in previous studies. In 2009, a similar statement was made by the American Dental Association [2, 3]. The United States Food and Drug Administration, however, stated in 2008 that mercury in amalgam can increase neural risk in children and pregnant women [4]. Some scientific experiments showed that amalgam restorations in the oral cavity keep releasing human-absorbable mercury vapor [5-8]. Other studies

\footnotetext{
* Correspondence: Liawyp@csmu.edu.tw

${ }^{2}$ Department of Public Health and Institute of Public Health, Chung Shan Medical University, No. 110 Sec. 1 Jianguo N. Road, Taichung City 40201, Taiwan

${ }^{3}$ Department of Family and Community Medicine, Chung Shan Medical University Hospital, Taichung, Taiwan

Full list of author information is available at the end of the article
}

have reported significant associations between mercury concentration in urine or in blood and quantities of amalgam restoration or number of total faces in amalgam restoration [9-11]. Furthermore, occupational studies on mercury exposure provided a strong association between mercury metal and the degeneration of the nervous system [12]. Inorganic mercury chloride $\left(\mathrm{HgCl}_{2}\right)$ at 0.025 to $25 \mu \mathrm{M}$ has been associated with both neuronal degeneration and perturbed excitability [13]. Hock and colleagues have reported a two-fold increase in mercury levels among patients with Alzheimer's disease (AD) when compared to control counterparts [14]. The influence of mercury on AD is not well understood. However, it has been demonstrated that mercury can dramatically promote heparin-induced aggregation of R2, the Alzheimer's tau fragment [15].

$\mathrm{AD}$ has been regarded as an unsolved, irreversible, and incurable brain neuron degeneration. AD patients normally have difficulties retrieving memory. They exhibit behavioral change as the disease progresses. Eventually, the disease leads to loss of control of body functions [16-18]. Being the most common type of dementia, AD 
is most often diagnosed in individuals 65 -years old and older [19]. One study reported that in 2006, the worldwide prevalence of Alzheimer's disease was 22.6 million while it has been predicted that by 2050, 1 in 85 people will suffer from AD [20]. From 2000-2010, someone in America was reported with AD every $68 \mathrm{~s}$. Deaths due to $\mathrm{AD}$ were reported at $68 \%$ while those resulting from heart diseases were observed to have decreased [21]. According to the Taiwan Alzheimer's Disease Association, an estimated $3.5 \%$ of Taiwanese will suffer from dementia by 2050 . AD, the most common type of dementia, is of critical importance in public health. The Alzheimer's Association in the USA claimed there is no association between silver dental fillings (known as amalgam fillings) and $\mathrm{AD}$ [22]. However, the impact of amalgam fillings on the development of $\mathrm{AD}$ is not well understood [23, 24]. Aging is considered to be a major risk factor for $A D$ $[25,26]$. This study aimed to investigate the association between dental amalgam fillings and $\mathrm{AD}$ in the Taiwanese population 65-years and older.

\section{Methods}

The study was conducted using the Longitudinal Health Insurance Databases (LHID 2005 and 2010). The databases comprise secondary data released to the public for research purposes; hence, this study was exempted from full review by the Institutional Review Board. Subjects included citizens who were $\geq 65$ years at study end in 2010. The basic characteristics of the study subjects included births, gender and income. Dental amalgam fillings were coded as $89001 \mathrm{C}, 89002 \mathrm{C}, 89003 \mathrm{C}, 89101 \mathrm{C}$, $89102 \mathrm{C}$, and $89103 \mathrm{C}$ in the national health insurance research database (NHIRD), where 89001C indicates single-face amalgam restoration, $89002 \mathrm{C}$ indicates twoface amalgam restoration, and $89003 \mathrm{C}$ indicates threeface amalgam restoration. The following codes, 89101C, $89102 \mathrm{C}$, and 89103C, represent single-surface, two- and three-surface amalgam restoration in specific cases. Individuals with $\mathrm{AD}$ were diagnosed using International Classification of Diseases, Ninth Revision, Clinical Modification (ICD-9-CM) code 331.0.

Data analyses were performed using the SAS 9.3 software package (SAS Institute Inc., Cary, NC, USA). Multiple logistic regression analysis was used to estimate the association between dental amalgam fillings and AD. The number of times and accumulated faces that a patient received amalgam fillings during 2001-2010 were regarded as independent variables while AD was considered as the dependent variable. Adjustments were made for age, gender, income, and residential region.

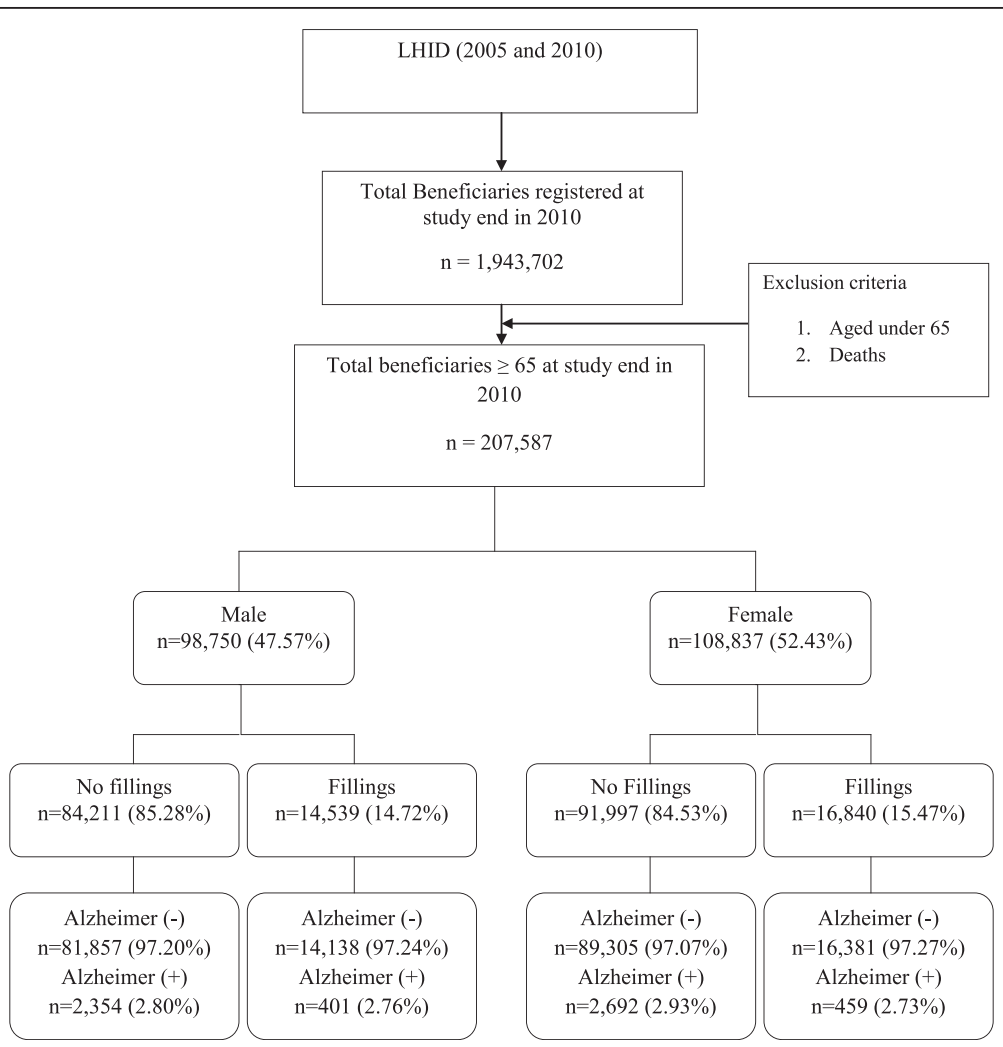

Fig. 1 Flow chart showing amalgam fillings and Alzheimer's disease (2000-2010) 


\section{Results}

In total, 207,587 individuals 65-years old and above were analyzed (Fig. 1). Generally, $2.76 \%$ of men exposed to amalgam fillings and $2.8 \%$ of their unexposed counterparts were diagnosed with $\mathrm{AD}$ as were $2.73 \%$ of women exposed to amalgam fillings and $2.93 \%$ of their unexposed counterparts. Table 1 shows the demographic characteristics of individuals with and without $\mathrm{AD}$. The mean age of individuals with $\mathrm{AD}$ was significantly higher than of those with no $\mathrm{AD}(79.36 \pm 7.14$ vs. $74.87 \pm 6.89, p<0.001)$. There was no significant difference in the gender distributions of AD. Subjects with and without AD were categorized into four levels by income. The percentages of subjects with $\mathrm{AD}$ were $41.86,25.70,31.59$, and $0.85 \%$ by income ranging from $1-20,000,20,001-40,000$, and $>40,000$ respectively. Income distributions were significantly different among $\mathrm{AD}$ and non-AD individuals. Central, South and Taipei regions had high prevalences of the disease. Individuals exposed to amalgam fillings had a higher risk of Alzheimer's disease [odds ratio $(\mathrm{OR})=1.105,95 \%$ confidence interval $(\mathrm{CI})=1.025-1.190]$ after adjusting for age, gender, income, and residential region (Table 2). Further analysis was made to assess disease risks by gender. The ORs for AD were 1.07 (95\% CI $=0.962-1.196)$ in men and $1.132(95 \% \mathrm{CI}=1.022-1.254)$ in women (Table 3$)$.

\section{Discussion}

This is the first study to investigate the association between dental amalgam fillings and $\mathrm{AD}$ disease using large-scale data. The study results show that women exposed to mercury amalgam fillings were 1.132 times more likely to have Alzheimer's disease than were their non-exposed counterparts. These findings are similar to those of previous studies that have reported elevated levels of plasma mercury in subjects with $\mathrm{AD}$ in comparison with their healthy controls [14, 27]. Moreover, mercury has been suggested as an important toxic element in AD [28]. Since the launching of the National Health Insurance (NHI) in Taiwan, the coverage rate was $97 \%$ by 2001 and $99 \%$ by $2009[29,30]$. The NHI has been responsible for the payment of amalgam fillings since 2004. The association between amalgam fillings and $\mathrm{AD}$ may have been underestimated considering that the number of amalgam fillings from 2001-2010 may not represent the actual fillings during the patients' lifetimes. However, people who had multiple amalgam fillings from 2001-2010 were more likely to have subsequent fillings. The NHIRD contains dental records of every beneficiary limited to $2001 \sim 2010$. Regarding the individuals without dental amalgam fillings, it is possible that this patient group may have had amalgam fillings earlier in their

Table 1 Baseline characteristics of study subjects

\begin{tabular}{|c|c|c|c|c|c|}
\hline \multirow[t]{3}{*}{ Variable } & \multirow{2}{*}{\multicolumn{2}{|c|}{$\begin{array}{l}\text { Alzheimer's disease } \\
(n=5,906)\end{array}$}} & \multirow{2}{*}{\multicolumn{2}{|c|}{$\begin{array}{l}\text { No Alzheimer's disease } \\
(n=201,681)\end{array}$}} & \multirow[t]{3}{*}{$p$-value } \\
\hline & & & & & \\
\hline & No. & $\%$ & No. & $\%$ & \\
\hline Age (year) & $79.36 \pm 7.14$ & & $74.87 \pm 6.89$ & & $<.0001$ \\
\hline Sex & & & & & 0.1496 \\
\hline Men & 2,755 & 46.65 & 95,995 & 47.60 & \\
\hline Women & 3,151 & 53.35 & 105,686 & 52.40 & \\
\hline Income (NT\$) & & & & & $<.0001$ \\
\hline Dependent & 2,472 & 41.86 & 84,740 & 42.02 & \\
\hline $1-20,000$ & 1,518 & 25.70 & 44,260 & 21.95 & \\
\hline $20,001-40,000$ & 1,866 & 31.59 & 69,890 & 34.65 & \\
\hline$>40,000$ & 50 & 0.85 & 2,791 & 1.38 & \\
\hline Region & & & & & $<.0001$ \\
\hline Area 1(Taipei) & 1,659 & 28.09 & 65,573 & 32.51 & \\
\hline Area 2 (Northern) & 868 & 14.70 & 26,761 & 13.27 & \\
\hline Area 3 (Central) & 1256 & 21.27 & 36,693 & 18.19 & \\
\hline Area 4 (Southern) & 1,247 & 21.11 & 34,690 & 17.20 & \\
\hline Area 5 (Kao-Ping) & 739 & 12.51 & 32,141 & 15.94 & \\
\hline Area 6 (Eastern) & 137 & 2.32 & 5,823 & 2.89 & \\
\hline Amalgam filling & & & & & 0.2274 \\
\hline None & 5,046 & 85.44 & 171,162 & 84.87 & \\
\hline Yes & 860 & 14.56 & 30,519 & 15.13 & \\
\hline
\end{tabular}

Age was mean \pm S.E 
Table $\mathbf{2}$ Logistic regression analysis of factors associated with Alzheimer's disease

\begin{tabular}{|c|c|c|}
\hline \multirow[t]{2}{*}{ Variable } & \multicolumn{2}{|c|}{ Logistic regression model } \\
\hline & $\overline{\mathrm{OR}}$ & $95 \% \mathrm{Cl}$ \\
\hline \multicolumn{3}{|l|}{ Amalgam fillings } \\
\hline None & 1.000 & - \\
\hline Yes & 1.105 & $1.025-1.190$ \\
\hline Age & 1.087 & $1.083-1.090$ \\
\hline \multicolumn{3}{|l|}{ Sex } \\
\hline Female & 1.031 & $0.976-1.088$ \\
\hline Male & 1.000 & - \\
\hline \multicolumn{3}{|l|}{ Income (NT\$) } \\
\hline Dependent & 1.374 & $1.287-1.466$ \\
\hline $1-20,000$ & 1.287 & $1.195-1.386$ \\
\hline $20,001-40,000$ & 1.000 & - \\
\hline$>40,000$ & 1.175 & $0.883-1.565$ \\
\hline \multicolumn{3}{|l|}{ Region } \\
\hline Area 1 (Taipei) & 0.735 & $0.675-0.800$ \\
\hline Area 2 (Northern) & 1.000 & - \\
\hline Area 3 (Central) & 1.127 & $1.032-1.232$ \\
\hline Area 4 (Southern) & 1.226 & $1.120-1.341$ \\
\hline Area 5 (Kao-Ping) & 0.734 & $0.672-0.821$ \\
\hline Area 6 (Eastern) & 0.732 & $0.609-0.880$ \\
\hline
\end{tabular}

Odds ratio was adjusted for age, gender, insurance level, and residential region $O R$ odds ratio, $\mathrm{Cl}$ confidence interval

life, and before 2001, removed them or replaced them with other dental materials, such as gold alloys or ceramics. There are also root filled teeth in jaws. Some root fillings, especially the retrograde root fillings, often contain mercury amalgam. In this study, the control group was not a "pure" non-exposure group because its individuals may have been exposed before 2001. Of course, prior to 2001, exposure to amalgam fillings might have either been lesser or greater in the exposure than the non-exposure group, and vice versa. This also applies for replacements with other dental materials, such as gold alloys or ceramics. However, there may have been non-differential misclassification at baseline which might have resulted in underestimation. From our findings, however, the results are significant implying higher risk of exposure. Even though the NHIRD could not provide complete information on the exact number of fillings and $\mathrm{AD}$, amalgam fillings from 2001-2010 could equally be representative of the total number of fillings during a patient's life. The same assumption was made for accumulated faces. Accumulated faces are the sum of the number of faces of each amalgam filling .

AD is often diagnosed among older people. This explains why subjects 65 -years old and above were used in
Table 3 Characteristics of people with amalgam fillings in both genders

\begin{tabular}{|c|c|c|c|c|}
\hline \multirow[t]{3}{*}{ Variable } & \multicolumn{4}{|c|}{$\underline{\text { Logistic regression model }}$} \\
\hline & \multicolumn{2}{|l|}{ Men } & \multicolumn{2}{|c|}{ Women } \\
\hline & $\mathrm{OR}$ & $95 \% \mathrm{Cl}$ & $\mathrm{OR}$ & $95 \% \mathrm{Cl}$ \\
\hline \multicolumn{5}{|l|}{ Amalgam fillings } \\
\hline No & 1.00 & - & 1.00 & - \\
\hline Yes & 1.07 & $0.962-1.196$ & 1.132 & $1.022-1.254$ \\
\hline Age & 1.09 & $1.084-1.096$ & 1.085 & $1.080-1.090$ \\
\hline \multicolumn{5}{|l|}{ Income (NT\$) } \\
\hline Dependent & 1.278 & $1.156-1.413$ & 1.455 & $1.335-1.585$ \\
\hline $1-20,000$ & 1.162 & $1.052-1.284$ & 1.452 & $1.297-1.625$ \\
\hline $20,001-40,000$ & 1.00 & - & 1.00 & - \\
\hline$>40,000$ & 0.945 & $0.656-1.360$ & 1.770 & $1.113-2.815$ \\
\hline \multicolumn{5}{|l|}{ Region } \\
\hline Area $1^{\mathrm{a}}$ & 0.838 & $0.740-0.950$ & 0.650 & $0.579-0.730$ \\
\hline Area $2^{\mathrm{b}}$ & 1.00 & - & 1.00 & - \\
\hline Area $3^{c}$ & 1.302 & $1.142-1.484$ & 0.991 & $0.878-1.118$ \\
\hline Area $4^{d}$ & 1.409 & $1.234-1.610$ & 1.087 & $0.963-1.228$ \\
\hline Area $5^{e}$ & 0.801 & $0.692-0.929$ & 0.695 & $0.606-0.796$ \\
\hline Area $6^{f}$ & 0.881 & $0.685-1.134$ & 0.611 & $0.466-0.800$ \\
\hline
\end{tabular}

Odds ratio was adjusted for age, income, and residential region

${ }^{a}$ Area 1 (Taipei): Taipei City and County, Yilan County, Keelung City, Kinmen County, and Lienhiang County)

${ }^{\mathrm{b}}$ Area 2 (Northern): Taoyuan County, Hsinchu County, Miaoli County, and Hsinchu City

'Area 3 (Central): Taichung City, Taichung County, Changhua County, and Nantou County

${ }^{\mathrm{d}}$ Area 4 (Southern): Tainan City and County, Chiayi City and County, Yunlin County eArea 5 (Kao-Ping): Kaohsiung City and County, Pingtung County, Penghu County fArea 6 (Eastern): Hualin and Taitung County

this study. Molecular lesions have been observed in more than $80 \%$ of senile AD brains [31]. A study showed that low income predicts the risk of developing incident AD [31]; hence, income was adjusted in this study. Environmental pollutants, such as heavy metal contaminations in ground water, contribute to varying levels of dietary mercury. Residential regions were adjusted because higher concentrations of mercury have been reported in western townships [32].

In this study, it is assumed that mercury released from amalgams would initiate AD. However, it would also be possible that oral exposure to nickel, palladium, chromium or cobalt might also be a cause of AD. Some people who visit the dentist might have a higher chance of getting amalgam restorations but also of getting cast restorations, such as crowns or bridges. In Asian countries nickel-based alloys are often used for this treatment. However, the National Health Insurance Database does not provide data on crowns and bridges partly because they are considered as advanced prosthodontic treatments for both esthetics and function. Moreover, 
they are more costly than amalgam restorations. The authors believe that crowns and bridges are a concern yet are less critical than amalgam restoration due to the following reasons: (1) The frequency of getting crowns and bridges is lower compared to amalgam usage. Amalga is indicated when early caries are present. Crowns are indicated when the tooth structure is severely destroyed possibly due to severe caries while bridges are indicated in edentulous areas. (2) Most of the crowns and bridges are porcelain-fusedmetal. That is, they are covered by porcelain with a natural-tooth-like look. The degree of metal exposure to the oral cavity is less. Even with all-metal crowns and bridges, the surfaces of the prosthesis are highly polished to decrease the abrasion of the metals. Therefore, effects due to oral exposure to nickel, palladium, chromium or cobalt were possibly minimized.

\section{Conclusions}

After adjusting for age, income and residential region, women exposed to mercury amalgam fillings were 1.132 times more likely to have $\mathrm{AD}$ than were their nonexposed counterparts.

\section{Abbreviations}

AD: Alzheimer's disease; Cl: Confidence interval; ICD-9-CM: International Classification of Diseases, Ninth Revision, Clinical Modification; LHID: Longitudinal health insurance database; NHIRD: National health insurance research database.

\section{Competing interests}

The authors declare that they have no competing interests.

\section{Authors' contributions}

YHS contributed to the conception and design of the study, acquisition of data, and drafting of the manuscript. ONN contributed to the interpretation of the data, drafting and critical revision of the manuscript for important intellectual content. JYH carried out statistical analysis, interpretation of data and revision of the manuscript. YPL participated in the conception, design, and coordination of the study, analysis of data, interpretation of the data and critical revision of the material. All authors read and approved the final version of the manuscript.

\section{Acknowledgments}

This research was supported by grants from the National Science Council (NSC 102-2815-C-040-040-B). The study is based partly on data retrieved from the National Health Insurance Research Database provided by the National Health Insurance Administration, Ministry of Health and Welfare, and managed by the National Health Research Institutes. The interpretation and conclusions contained herein do not represent those of National Health Insurance Administration, Ministry of Health and Welfare or National Health Research Institutes.

\section{Author details}

'School of Dentistry, Chung Shan Medical University, Taichung City 40201, Taiwan. ${ }^{2}$ Department of Public Health and Institute of Public Health, Chung Shan Medical University, No. 110 Sec. 1 Jianguo N. Road, Taichung City 40201, Taiwan. ${ }^{3}$ Department of Family and Community Medicine, Chung Shan Medical University Hospital, Taichung, Taiwan.

Received: 9 July 2015 Accepted: 28 September 2015

Published online: 12 November 2015

\section{References}

1. Visser H. Quecksilber-Exposition durch Amalgamfüllungen. Hüthig Buch Verlag; 1993.

2. SCENIHR E. The safety of dental amalgam and alternative dental restoration materials for patients and users. URL accessed on. 2008; 9(4):2013.

3. Association AD. AMA Statement on Dental Amalgam. ADA Positions Statements. 2002;2007:1-2.

4. Edlich R, Cross CL, Wack CA, Long III WB, Newkirk AT. The food and drug administration agrees to classify mercury fillings. J Environ Pathol Toxicol Oncol. 2008;27:303-5.

5. Clarkson TW, Friberg L, Nordberg GF, Sager PR. Biological monitoring of toxic metals. Springer Science \& Business Media; 2012.

6. Bangsi D, Ghadirian P, Ducic S, Morisset R, Ciccocioppo S, McMullen E, et al. Dental amalgam and multiple sclerosis: a case-control study in Montreal. Canada Int J Epidemiol. 1998;27:667-71.

7. Goering PL, Galloway WD, Clarkson TW, Lorscheider FL, Berlin M, Rowland AS. Toxicity assessment of mercury vapor from dental amalgams. Fundam Appl Toxicol. 1992;19:319-29.

8. Choi B. Risk assessment in dentistry: health risks of dental amalgam revisited. J Can Dent Assoc. 1996;62:328-32.

9. Englund GS, Dahlqvist R, Lindelöf B, Söderman E, Jonzon B, Vesterberg O, et al. DMSA administration to patients with alleged mercury poisoning from dental amalgams: a placebo-controlled study. J Dent Res. 1994;73:620-8.

10. Bratel J, Haraldson T, Meding B, Yontchev E, Ohman S, Ottosson J. Potential side effects of dental amalgam restorations. (I). An oral and medical investigation. Eur J Oral Sci. 1997;105:234-43.

11. Langworth S, Sällsten G, Barregård L, Cynkier I, Lind ML, Söderman E. Exposure to mercury vapor and impact on health in the dental profession in Sweden. J Dent Res. 1997;76:1397-404.

12. Brownawell AM, Berent S, Brent RL, Bruckner JV, Doull J, Gershwin EM, et al. The potential adverse health effects of dental amalgam. Toxicol Rev. 2005;24:1-10.

13. Xu F, Farkas S, Kortbeek S, Zhang FX, Chen L, Zamponi GW, et al. Mercuryinduced toxicity of rat cortical neurons is mediated through $\mathrm{N}$-methyl-Daspartate receptors. Mol Brain. 2012;5:30.

14. Hock C, Drasch G, Golombowski S, Müller-Spahn F, Willershausen-Zönnchen B, Schwarz P, et al. Increased blood mercury levels in patients with Alzheimer's disease. J Neural Transm. 1998;105:59-68.

15. Yang DJ, Shi S, Zheng LF, Yao TM, Ji LN. Mercury (II) promotes the in vitro aggregation of tau fragment corresponding to the second repeat of microtubule-binding domain: coordination and conformational transition. Biopolymers. 2010;93:1100-7.

16. McKhann GM, Knopman DS, Chertkow H, Hyman BT, Jack Jr CR, Kawas CH, et al. The diagnosis of dementia due to Alzheimer's disease: recommendations from the National Institute on Aging-Alzheimer's Association workgroups on diagnostic guidelines for Alzheimer's disease. Alzheimers Dement. 2011;7:263-9.

17. Grady CL, Haxby J, Horwitz B, Sundaram M, Berg G, Schapiro M, et al. Longitudinal study of the early neuropsychological and cerebral metabolic changes in dementia of the Alzheimer type. J Clin Exp Neuropsychol. 1988;10:576-96.

18. McKhann G, Drachman D, Folstein M, Katzman R, Price D, Stadlan EM. Clinical diagnosis of Alzheimer's disease: report of the NINCDS-ADRDA Work Group under the auspices of Department of Health and Human Services Task Force on Alzheimer's Disease. Neurology. 1984;34:939-44.

19. Brookmeyer R, Gray S, Kawas C. Projections of Alzheimer's disease in the United States and the public health impact of delaying disease onset. Am J Public Health. 1998;88:1337-42.

20. Brookmeyer R, Johnson E, Ziegler-Graham K, Arrighi HM. Forecasting the global burden of Alzheimer's disease. Alzheimers Dement. 2007;3:186-91.

21. Thies W, Bleiler L. 2011 Alzheimer's disease facts and figures. Alzheimers Dement. 2011;7:208-44.

22. Mutter J, Naumann J, Walach H, Daschner F. Amalgam risk assessment with coverage of references up to 2005. Gesundheitswesen. 2005;67:204-16.

23. Bates MN, Fawcett J, Garrett N, Cutress T, Kjellstrom T. Health effects of dental amalgam exposure: a retrospective cohort study. Int J Epidemiol. 2004:33:894-902.

24. Bates MN. Mercury amalgam dental fillings: an epidemiologic assessment. Int J Hyg Environ Health. 2006;209:309-16.

25. Kukull WA, Higdon R, Bowen JD, McCormick WC, Teri L, Schellenberg GD, et al. Dementia and Alzheimer disease incidence: a prospective cohort study. Arch Neurol. 2002:59:1737-46. 
26. Bachman D, Wolf PA, Linn R, Knoefel J, Cobb J, Belanger A, et al. Incidence of dementia and probable Alzheimer's disease in a general population: The Framingham Study. Neurology. 1993;43:515-9.

27. Gerhardsson L, Lundh T, Minthon L, Londos E. Metal concentrations in plasma and cerebrospinal fluid in patients with Alzheimer's disease. Dement Geriatr Cogn Disord. 2008;25:508-15.

28. Wenstrup D, Ehman WD, Markesbery WR. Trace element imbalances in isolated subcellular fractions of Alzheimer's disease brains. Brain Res. 1990;533:125-31.

29. Lu JF, Hsiao WC. Does universal health insurance make health care unaffordable? Lessons from Taiwan. Health Aff. 2003;22:77-88.

30. Chen YC, Yeh HY, Wu JC, Haschler I, Chen TJ, Wetter T. Taiwan's National Health Insurance Research Database: administrative health care database as study object in bibliometrics. Scientometrics. 2011;86:365-80.

31. Evans DA, Hebert LE, Beckett LA, Scherr PA, Albert MS, Chown MJ, et al. Education and other measures of socioeconomic status and risk of incident Alzheimer disease in a defined population of older persons. Arch Neurol. 1997:54:1399-405.

32. Huang HH, Huang JY, Lung CC, Wu CL, Ho CC, Sun YH, et al. Cell-type specificity of lung cancer associated with low-dose soil heavy metal contamination in Taiwan: an ecological study. BMC Public Health. 2013;13:330.

\section{Submit your next manuscript to BioMed Central and take full advantage of:}

- Convenient online submission

- Thorough peer review

- No space constraints or color figure charges

- Immediate publication on acceptance

- Inclusion in PubMed, CAS, Scopus and Google Scholar

- Research which is freely available for redistribution 